To appear in Education as Change 18 (1), 2014, pp 47-61

\title{
Liberated to Learn: Teacher Education as Transformation of Relationships
}

\author{
Ora Kwo \& Dennis Fung \\ The University of Hong Kong
}

\begin{abstract}
$\underline{\text { Abstract }}$
This paper reports on a process of curriculum innovation for a pedagogy course with a focus on the perceptual gaps between teacher educators and student teachers. As a collaborative inquiry by teacher educators, it was a response to government-led education reform for a new subject at senior secondary level, Liberal Studies, which aimed to cultivate citizenship with humanitarian values.

Observing critical discourse and community learning as desirable pedagogical principles to nurture a new generation of teachers for social awareness and commitment to citizenship, the curriculum innovation began with recognition of student teachers' lack of readiness to embrace such learning orientations due to the pre-university approach to learning for examination performance. The challenges were met with the design of assessment tasks that shaped independent thinking and collaborative inquiry, while building relationships in multiple human and conceptual dimensions. Through analysis of a flow of episodes, the paper captures the meaning of the processes of liberation to learn, and concludes with depiction of a growth model for transformation of relationships amidst a performance-related assessment culture.
\end{abstract}

Key words: learning to teach, curriculum reform, pedagogy, critical discourse, Hong Kong 


\section{Introduction: Changing Education amidst Globalization}

Over the last half century, our world has become increasingly globalized and pluralist. UNESCO's International Commission on Education for the Twenty-first Century (Delors, 1996) identified four pillars of education - learning to know, learning to do, learning to live together, and learning to be. This comprehensive outlook helped to re-focus education with inclusion of the latter two which are related to citizenship and peace. Hershock, Mason and Hawkins (2007, p.331) pointed out the broad implications of the meaning of educating whole persons for whole lives:

In the context of a world in which it is apparently no longer possible to rest content with promoting the tolerance of difference within and among societies, profound questions emerge regarding how to encourage and enable the appreciation of difference as the basis for mutual contribution.

In this perspective, education at all levels is viewed less as a matter of transferring knowledge than as generative knowing in an adventure. This paper responds to such a call for paradigmatic change in education in an increasingly globalized world which is accompanied by ubiquitous governmental initiatives for educational reform.

The specific setting is Hong Kong, which in 1997 underwent a transition from British colonial rule to become a self-governing Special Administrative Region of the People's Republic of China (Bray \& Koo, 2004). The first section of this paper introduces the scenario of curriculum reform for senior secondary school education. As teacher educators, we were interested to study the embedded issues, from which to design an innovative curriculum to challenge our own learning capacity while preparing a new generation of teachers to face challenges. The paper presents discoveries of what is meant by being 'liberated to learn' in the process.

\section{Conceptualising Liberal Studies for Curriculum Reform}

Hong Kong's transition from colonial rule brought a new era for education with a comprehensive review of education leading to blueprints for educational reforms (e.g. Education Department, 1999; Curriculum Development Council, 2001, 2002). One major dimension of the reform pushed for a departure from rote-learning for examinations. An interdisciplinary subject, Liberal Studies, was introduced as a mandatory subject (alongside Chinese Language, English Language and Mathematics) in senior secondary schooling. The changes (Curriculum Development Council \& Hong Kong Examinations and Assessment Authority, 2007, p.5) were targeted to enable students:

0 to develop multiple perspectives on perennial and contemporary issues in different contexts (e.g. cultural, social, political and technological);

o to become independent thinkers so that they can construct knowledge appropriate to changing personal and social circumstances.

In its entirety, the curriculum content of Liberal Studies was construed as a resource for helping students to develop independent thinking rather than simply receiving a corpus of facts, concepts, and skills (Deng, 2009). Each module in Liberal Studies is organised around themes framed as key issues for inquiry. In addition to the mandatory modules, each student is required to conduct a research project 'Independent Enquiry Study’ over a two-year period.

Liberal Studies, comparable to Liberal Arts and General Education in Western countries, is envisaged as a vehicle for cultivating extensive changes against a tradition of competitive learning and teacher-controlled classrooms (Chan \& Watkins, 1994). The challenge to engage in critical review of conflicts and controversial issues seem pertinent but also distant, calling for multiple levels of changes. With its emphasis on enquiry-based learning from multiple 
perspectives on perennial and contemporary issues, Liberal Studies is also identified as a precursor to traditional subjects, like physics and mathematics, in teaching argumentation and independent thinking (Fung \& Howe, 2012). In essence, Liberal Studies is expected to contribute to the attainment of the goals of the senior secondary curriculum (Education and Manpower Bureau, 2004, p.8). The intention is to help each student to become an informed responsible citizen of the local, national and global identity with respect for cultural pluralism.

Other Asia-Pacific countries have also acknowledged the need for curriculum reform to provide their students with a competitive edge to respond to changes worldwide, such as globalisation and sustainable development, as well as economic transformation (Fung \& Yip, 2010). Singapore's 'Teach Less Learn More' initiative (Ng, 2008) aimed to cultivate students' problem-solving and critical-thinking skills. In a similar vein, the Philippines introduced a new integrated subject, 'Makabayan', to promote cross-contextual knowledge and to create multi-faced basic education (Almonte-Acosta, 2011). These reform initiatives resonate well with global curricular development trends in which higher degrees of intellectual autonomy in classrooms are expected - e.g. Yackel \& Cobb’s (1996) focus on building inquiry-based discussion and argumentation in mathematics.

\section{Confronting Challenges to Teacher Education}

Given the ambitious curriculum reform, a pivotal locus for change is how teachers are being prepared to enter the profession. This paper is framed within teacher educators' own quests for knowledge when considering the nature of student teachers from traditional learning orientations fit for high performance in public examinations rather than the enquiry learning modes expected of the Liberal Studies curriculum. Another major contextual challenge comes from the university culture in which individual teachers tend to work in isolation. Macfarlane (2012, p.12) noted that intellectual leadership in university is a problematic concept: intellectuals may be self-absorbed individuals, coping with conceptual complexity but not sufficiently responsible to be put in charge of collective activities.

A process of curriculum innovation was launched for the pedagogy course for Year 3 student teachers ${ }^{1}$ by two teacher educators who are related as learning partners in collaborative inquiry. The inquiry was motivated by shared concerns, articulated as critical research questions:

o How can students from traditional schooling be nurtured into a new generation of Liberal Studies teachers?

o What pedagogical shifts can be identified for the intended transformation?

0 What can teacher educators learn from encountering conflicts in order to be liberated to learn, and to facilitate this liberation for student teachers?

These questions were related to wider issues beyond classroom pedagogy, as the meaning of liberation was central to the quest. This paper analyses the journey to bridge the gap between the ambition of curriculum reform and the reality that needed to be addressed by teacher educators and student teachers.

\section{Liberating a Space for Collaborative Inquiry}

This paper is co-authored ${ }^{2}$ with a shared concern to take heed of modelling the qualities to be cultivated in student teachers. Reality is often governed by multiple systems maintaining the

\footnotetext{
${ }^{1}$ This course is the second of a series of three in Years 2 - 4 for students of Liberal Studies to be prepared for entry into the teaching profession.

${ }^{2}$ The first author is the instructor of the innovative course, whereas the second author is a learning partner as a coinvestigator leading a project funded by a Teaching Development Grant of the University of Hong Kong.
} 
status quo, ranging from assessment of students' learning outcomes to measurement of teachers' accountability. We were aware that innovating teachers often enter a vulnerable state. As noted in Kwo's (2010, p.172) study of a community for curriculum development:

In spite of thoughtful planning and purposeful skilled actions, one can never be sure that the actions will convey the meaning they were intended to have for the students... Teaching improvement is not about validation or simplistic acceptance / rejection of students' voices as private pedagogical decisions of the teacher. The critical focus should be about opening up the space to turn the vulnerability into an ongoing inquiry.

Such a critical focus affirmed for us the significance of collaborative inquiry to move beyond the sense of vulnerability. We were motivated to liberate the learning capacity of student teachers by responding to our own anxieties on how the innovations might overcome our students' natural sense of alienation, given their previous 'learning' orientation in schools. As alerted by Shor and Freire (1987, p.7-8), a serious epistemological question is about our ignorance of the distinct moments in the way learning takes place. When knowledge is produced in a place far from students, we reduce the act of knowing into a mere transference of existing knowledge. By recognizing constraints against transformation and critiquing simplistic knowledge-transference, we aspire to model active sceptical learning to open our students from high-score examination performance at university entrance to becoming curious, critical and creative. Accordingly, we designed the pedagogy course curriculum with a principle of assessment for learning, as described in the design:

With a primary focus on integration between coursework and Teaching Practicum, the assessment calls upon student-teachers to develop a capacity for professional learning, which is much more than intellectual learning, demanding sensitivity to integrate parallel courses to build a foundation of understanding about the nature of Liberal Studies... The curriculum is designed to recognize contributions from all student-teachers under mentoring support of the course instructor. Within a planned structure, the relationship between teaching and learning is not hierarchical, but synergetic and open, with the object of inquiry as a mystery to be revealed along the way. Likewise, the course instructor and student-teachers are related as a community of learners, each contributing to make the community vital and vibrant.

\section{Innovation in Assessment Design}

The curriculum innovation was launched with a strategic pedagogical push through assessment design, while we took into consideration the curriculum design principles of the reform for senior secondary education (Education and Manpower Bureau, 2005):

o integrating, applying, consolidating and broadening the foundational knowledge through a range of contemporary issues;

o perspectives and concepts essential to the understanding of issues of human concern, with ability to transfer and apply them to the understanding of new issues;

Overall, our rationale for the assessment tasks for the pedagogy course was based on what to anticipate as outcomes for learning. In order for our student teachers to be prepared for Teaching Practicum with theory-practice integration, we aimed to expose them to challenges by which they could engage in independent thinking and community dialogues. The content of the curriculum is 
fluid as the object of inquiry open to knowledge-production from community discourse ${ }^{3}$. Through the initial assessment task which invited a plunge at the deep end of leading a class seminar in response to the movie 'The Age of Stupid', ${ }^{4}$ our students were engaged in a series of activities:

(a) identify a key problem for research as an object of inquiry for a class seminar;

(b) plan the class seminar with construction of critical questions and provision of stimulating materials;

(c) study related literature on pedagogical content knowledge to support the work in leading the critical dialogue expected of Liberal Studies curriculum; and

(d) engage in evaluation of teaching and learning in the light of theoretical understanding.

The process was facilitated with tutorials before and after each seminar, for knowledge production at various levels of evaluation. Critical dialogues were conducted among students as peers before tutorials with the course instructor, culminating in conceptualization of pedagogical content knowledge for Liberal Studies. In essence, the curriculum was strategically designed to bring about the plunge, followed by scaffolding of a series of critical dialogues for planningteaching-evaluation.

\section{Inquiry into Curriculum Innovation}

From the outset of innovation, we were aware of the potential gap between our rational planning and our student teachers' diverse learning orientations. This gap may challenge their epistemological beliefs and expectations of how to learn to become Liberal Studies teachers. We anticipated conflicts in mutual expectations, despite our justification of the rationale for assessment design. We were ready to conduct our inquiry as laid down by our research questions.

\section{Approach to Data-Analysis}

Our data were not merely accumulated and collected as a product of our teaching and learning in class sessions, but naturally captured in authentic settings over distinct moments for learning for us and for our student teachers. We felt connected to what Samuel (2009, p.11-12) suggested about data-gathering for studying the individual's life. We were studying our own professional learning life when placed in different positions of telling in different research contexts: in the lecture classroom; in the researcher's office; in our reflective journals and our reflexive dialogues. Another major data source for our co-inquiry came from our Moodle website for teaching and learning. The online documentation provides a trail of a lived curriculum for our reflection on practice.

These two data sets were repeatedly reviewed before, during and after the Teaching Practicum to sustain our inquiry, when questions emerged for our dialogues, by which we refined our curriculum development. Instead of transferring others' knowledge, we took critical discourse and community building as our major pedagogical stances for understanding our modelling effect, as we responded to student-teachers' learning progress in assessment tasks. Our own knowledge construction was grounded in practical experience, as revealed in our continual evaluation of teaching and learning, and supported by related reading. We decided to select the most salient episodes to reveal how challenges and opportunities of being liberated to learn can best be

3 The generated themes included: Renewable Energy; Disappearing Rainforest \& Global Environmental Citizenship; Water Crisis; Consuming Lifestyle; Education for Sustainable Development; Food Shortage; Climate Change; Human Relationship with Environment.

${ }^{4}$ As a semi-documentary, news clips were collated to construct an imaginary narrative of our planet running out of life resources by 2055, with archives of interviews showing the process of our planet's destruction due to social, economic, environmental and cultural factors. 
manifested. Presented in a chronological sequence, each episode is narrated by the course instructor.

\section{Pre-Practicum}

As an innovative assessment, students-led seminars were received with positive responses from the initial groups. Students generally demonstrated impressive skills in information search to identify critical issues. Amidst what appeared to be a smooth flow, a learning moment was brought by Cream: ${ }^{5}$

Cream came to my office for some consultation to finalize preparation for a seminar on Food Allocation. The visit followed a tutorial with me two days previously when all four students of the group were present.

For some reason, Cream seemed to intend the discussion to be brief so that $\mathrm{s} / \mathrm{he}$ could move to other tasks. When I had listened to the planned sequence of activities, I was puzzled by the use of certain terms and doubted whether the conceptual meanings had been appropriately grasped. There seemed to be more attention to the flow of activities than a search for the critical focus. I tried to raise my queries, only to find a lack of receptive listening. Apparently there was a clash of expectations - I wanted to work with Cream on how to proceed from my queries, whereas Cream just wanted my approval of the plan. S/he added: "My work has always been considered good by other professors here, and you are the only one who criticizes me."

I was taken aback that the effort to communicate had been received with a feeling of rejection. I sensed that there were more issues than we could handle within the few minutes before my next meeting, and suggested that Cream might gather the group members again for considering my questions. My next surprise was that $\mathrm{s} /$ he anticipated no more group meetings, as s/he was expected to finalize the plan.

I then made a bold suggestion that they should postpone the seminar till the following week, to gain enough time to address my queries. Cream continued to express dissatisfaction, and asked, "Why can't a capable student take care of the task on behalf of others?" I then proceeded with some re-iteration of the significance of collaborative learning embedded in the assessment task. What dawned on me was that s/he had never been convinced of this pedagogical principle even though it was clearly stated in the government's curriculum reform documents around which the pedagogy course was structured.

I suggested that we should meet again to continue the conversation after my next appointment. S/he then blurted, "You mentioned in the first session that we should not train robots - it may be a good line to quote from a book, but you are too idealistic. If we were not robots, we would not have been here." There came knocks on my door - time for a pause from our unfinished conversation. I invited Cream to come back one hour later, and s/he agreed to search for some content materials for our further discussion.

Punctually Cream knocked at my door after one hour. This time, s/he brought a group member. Our conversation went more deeply into the dimensions of knowledge, skills and attitude. I picked up and challenged Cream on inconsistencies of sceptical remarks. The challenges came back, "Do you want me to think like you?" It was as if I finally managed to push this resilient mind to a corner, "Are you happy about issues of injustice that you have just enlisted?" I received a prompt response in negation.

\footnotetext{
${ }^{5}$ This is an account of my reflections on a dialogue with a student whom I consider intellectually robust. For anonymity, gender-neutral names (Cream, Astor and Kim) are used for the following accounts.
} 
I became more intrigued by the meaning of university education for Cream. "Why do you want to be in university, apart from scoring high grades?" After a long pause, the response was pretty standard: "To learn..."

"What does learning involve?"

"Knowledge, skills - but not attitude, which is not so measurable."

Somewhat inefficiently, we managed to work out a plan for the seminar led by Cream's group. During the process, Cream was confronted to re-visit the longstanding mindset while my own horizon was challenged. I felt as if I was puffing along to engage in what Cream might find irrelevant for the immediate agenda, but on which I was nevertheless willing to sustain a dialogue...

Through this episode, written up immediately afterwards, we asked ourselves, as teacher educators, whether we genuinely believe in modelling for our students. If we pursue a dialogue with a forceful stance, are we taken as imposing and disrespectful of students' stances? What can we learn about the pedagogy of critical discourse? We came to realize that while our students are ready to abide by the expectations of assessment tasks, the intended rationale is not necessarily shared by all. The general 'successful' motions in the class can continue in an absence of critical dialogue. It was through a personal space of tutorials with small groups that our student teachers became more deeply engaged in critical thinking. Yet, the general courtesy and superficial rapport might have inhibited deep inquiry and genuine relationship-building.

The close encounter of Cream offered a glimpse of how assessment tasks were merely taken as instruments for classifying grades, regardless of the intended rationale. Cream's approach to group work revealed a disbelief in collaborative learning, while abiding by the assessment requirements. It was as if the tutor was challenged to a test on how deeply the advocacy of critical discourse could be put into practice. With boldness in self-expression, Cream spoke to a belief in examination and even robot-training, against the spirit of Liberal Studies. The dialogue was pushed to a sharper confrontation, from which a new rapport emerged for both sides. Critical discourse was made possible with a developing relationship.

\section{During-Practicum}

Teaching Practicum is meant to be an extended period in school placement for theory-practice integration. Astor's crisis provided another episode for learning about the gap between intention and reality.

In the sixth week of the eight-week practicum, I received a message from a colleague who had made the second supervisory-assessment visit ${ }^{6}$ to Astor with an alarm about a possible failed grade. That was a surprise to me, as I always knew Astor as thoughtfully courageous to voice ideas. Astor also exercised impressive leadership in building group dynamics for the seminar. With a sense of puzzlement, I organised an urgent visit to Astor before the final supervisory-assessment visit that had been arranged in the final week.

Before entering the classroom, I was greeted by Astor who seemed rather nervous. Throughout the lesson I observed, it was difficult to trace any moment of teaching and learning from this intelligent student who seemed to have radically turned into a

\footnotetext{
${ }^{6}$ We had a long-standing system of three visits for each student teacher for the purposes of supervision and assessment.
} 
classroom administrator. Multiple commands were issued without meaningful inputs, leaving many moments of chatty off-task behaviour, and bringing further rounds of ineffective commands. At the end of the lesson, my candid feedback brought Astor to see the problem of an absence of enabling acts of teaching that can facilitate learning. The threat of failing in Teaching Practicum became serious. The puzzle to me was about Astor's obsession with administrative commands. For a proper discussion, I asked Astor to meet me at my office after school with the learning materials so that we could go through the puzzles together. Before the meeting, I sent an email message of encouragement:

"I remain confident that you are a good learner. This brief message is sent to invite you to think about the nature of learning to become a professional teacher. It is not about going from $A-Z$, but a process of meaning-making from experiences. I look forward to our meeting."

I was determined to frame our meeting with a tone of support rather than assessment. During our discussion, I prompted reflections on what had happened. It dawned on us that the plan had been centred exclusively on intentions without parallel consideration of students' learning needs. It was assumed that the students from the high-achieving class were able to perform in response to commands, whereas the intentions to administer the tasks without meaningful support was dominated by the time constraint before uniform test for all classes of the same level. Somewhat in agony, Astor recalled how s/he had been convinced from university critical discourse that we should not be teaching to the tests. Yet, the administrative chore of assessment became such a strong focus of responsibility that the meaning of Teaching Practicum had been reduced to a superficial compliance to school routines. This insight was shocking to Astor as s/he insightfully spoke to the beginning of how the belief in education was given up. Paradoxically that shock became the turning point for seeking and bearing responsibility for the choice of action. The session was concluded with a sense of urgency for Teaching Practicum to begin anew within the remaining week.

In the meeting, we did not spend time on the logistics of planning, which was part of the conceptual knowledge that Astor had already been exposed to, only waiting to be actualized in practical experiences. Two days later, Astor sent me a well-constructed lesson plan. Built on some affirmation, I recommended a review of each segment with anticipation of how students might respond. I challenged the assumption that students would all obediently align with the intended behaviour listed in a logical plan. That helped Astor to further break down a complex task into stages with finer pedagogical considerations in the light of anticipated diverse responses. S/he responded to my urge for a revised plan, showing a much better focus on what students are expected to learn. My continual support was conveyed in the email:

"All in all, I think you have demonstrated commendable labour with leaps and bounds. Enjoy your teaching, and be curious about how students think... Enjoy your visitor's presence, as you can then share your understanding of challenges and possibilities."

At the end of the school day on which Astor expected the third supervisory-assessment visit, I had a knock at my office door. In came Astor, keen to take one short moment to share personally the relief that the assessment visit had concluded with appreciative feedback. S/he was confident to stride on with no more threat of failure. An email came soon afterwards:

"This has been a precious and painful experience. I want to thank you for your unfailing support to me throughout the difficult journey. With the intensive discussion and reflection during the week, I am only beginning to understand the 
meaning of teaching and learning. The gap that you always expressed concern during the course has been perfectly manifested. Now I feel able to see what it means for the first time. Without this awareness of the gap, I can never address it."

This episode began with a procedural routine of identifying problem cases during the Teaching Practicum for moderation to be arranged. The extra visit would have added weight to confirm the assessment made by the second supervisor-examiner. However, the scenario was turned into a challenge shared by both. Critical discourse took shape in a non-threatening sustainable manner, having stemmed from a crisis which called for professional support. Such support must be rooted in a strengthened rapport with a shared determination to confront the situation. When the student teacher was empowered to reach new discoveries, s/he could take off with onward quest. The supervisory support was not about inducing remedial learning on the technicality of lesson planning to tackle what appeared to be performance deficiency, but more about the courage to enter into less visible puzzling layers to understand and respond to unexpected circumstances.

The most salient outcome of the joint inquiry was recognition of the learning gap for a move from university to a school for practicum, having to cope with what was perceived as polemic ends between learning and assessment. For Astor, the exclusive attention to assessment was misguided by the polarization mentality, as evident in the administrative testing routines. Just as routinized, assessment of Teaching Practicum could equally be directed with ongoing polarization, as feedback could have confirmed the failure. Reaching for the inner capacity, Astor was able to move from learning to perform to a quest for renewed understanding. The journey towards resumption of balance for Astor during the final week of practicum was a process of being liberated to learn.

The gap between a teacher's intentions and students' expectations will always be there, alongside the gap between teacher educators' inculcation and student teachers' receptivity. Improvement in teaching and learning is not to be achieved by removing the gaps, which is impossible, but by recognizing them in order to address them, within the zone of proximal development, as advocated by Vygotsky (1978, cited in Kwo, 2010, p.162). The process of learning to teach is not about simplistic success or failure. It should be an unfailing sustainable interest to capture learning insights from what is going on.

\section{Post-Practicum}

In preparation for welcoming student teachers back to campus, I was conscious of the challenge of how to capture richness of the practicum experiences within the limited class time. I created a space for collaborative thinking, when three posters were set up on the classroom walls for inviting reflections on what they enjoyed, what they perceived as challenges and their aspiration for support. To ensure contributions from all (so that the discussion would not be dominated by only a few outspoken ones), each student was expected to present a voice written on a sticker which was later posted on a wall poster for group sharing.

Analysis of voices was conducted with rounds of interpretation of the commonly mentioned gaps between the officially documented Liberal Studies curriculum and the traditions in schools not in harmony with the reform philosophy. The gaps were conceptualized in two metaphorical images to evoke the quest for deeper meanings: the caged bird and the soldier struggling to survive. The sense of being caged was identifiable as the feeling of constraints from heavy curriculum materials expected to be covered without adequate time for learning exploration, the school culture of hierarchical relationship between teachers and students, and the environment of unquestioned rigid routines, all in contradiction to the aims of the Liberal Studies curriculum. On 
the other hand, the image of the struggling soldier reminded them of the painful survival in a lonely state without knowing where the enemy is and when the end of the battle will come. With the use of metaphors, the student teachers were put in touch with their puzzled feelings about the meaning of learning to teach.

When preparing for the final essay, Kim came to my office expressing worries. We had a lively discussion. An extract from Kim's final essay is presented here to illustrate a process of liberation from an old mindset.

I had a strong core value before my Teaching Practicum which I thought would remain for my entire career: commitment to facilitation for achievement. Achievement in this sense is measured by summative assessments including the public examination which I think would influence students' careers to a significantly large extent. Direct instruction is the pedagogy I preferred to adopt in order to optimize success. Almost all of my secondary school teachers made use of direct instruction, and I believed the pedagogy was costeffective in terms of the relatively small amount of time and effort needed by students to obtain a large amount of information. Questioning as a check of students' understanding was one of my main strategies to make direct instruction 'successful'.

My core value with my pedagogical conception was challenged in the group-led seminars before the Teaching Practicum, but it did not shift at all. While I was aware of the advantages of a student-centred approach in theory, I experienced difficulty constructing critical dialogues with students and responding to their unexpected utterances. With an unpleasant sense of failure, I almost concluded that student-centred learning is too ideal for a real classroom. My preference to direct instruction was strengthened..

In the Teaching Practicum, I was allocated to the worst class commonly referred as the jungle in the school. My mentor who has been teaching in the school for over 10 years told me that my only responsibility was to keep the students in class. I thought it was a joke, but as I came to face the reality, I found no better metaphor than the jungle to describe the class.

After the first two weeks during which I mainly used direct instruction to cover a considerable number of topics, I discovered mainly two types of students in the noisy class: those who were deadly asleep and those who never stopped chatting. One day, after another failure in the jungle, I was overwhelmed by frustrations. I realized that I was dreaming about happy lessons with obedient students.

I thought of giving up teaching them, and instead, giving them free time in my entire lesson, since they did not want to learn anything. However, my core value was too powerful to stop me from teaching them: I still wanted them to succeed in the future. It was a point that I decided to give up direct instruction which I thought was the most efficient pedagogy. Instead, I tried a student-centred approach which I hated.

For the first few times the lessons were still disastrous. My students easily got out of control and made irrelevant utterances, making the class even noisier. During my struggles, I talked to a visiting Teaching Practicum supervisor about whether direct instruction should still be encouraged for convenience of classroom management. I was given a reply with a smile, "If they do not know how they should behave, they need education." This message became my motto for the remaining Teaching Practicum.

After a long struggle, I finally had a lesson in which my students performed excellently, as we spent much time discussing the ethics of organ transplant. Rather than presenting overall pros and cons of organ transplant, I broke down the issue into smaller components and presented them as debate questions. My use of the three different 
scenarios evoked opinions, while exposing students to counter-arguments and inviting reevaluation of opinions. Although my lesson was not sophisticated enough to help them fully grasp the critical issues, my students seemed to enjoy seeing different perspectives when they could re-shape opinions from considering different factors, including the gender difference and age of patients.

My internal struggle to choose between teacher-centred direct instruction and studentcentred debating can be compared to serving food to children as a parent. Just as both the number of topics and depth of discussion on each topic cannot be achieved due to the limited class time, the serving of food must be compromised with consideration of quantity and quality. My preference for efficient direct instruction can be viewed as providing a great amount of junk food. I began to see that my students do not want junk food. Instead, they prefer a small amount of tasty food. Their natural need matches with what Liberal Studies aims to cultivate: life-long learning. By throwing a great deal of information at my students, I took away a chance for them to enjoy learning. I found that I was the one who should learn from my students in terms of the attitude toward learning.

I vaguely see a new core value emerging: commitment to facilitation for enjoyable learning. The teacher who is pressurized to use direct instruction to cover all the materials is both a victimizer to students and a victim under the current education system. The practicum of two months was not sufficient to shift my core value cultivated from over 10 years, but I am open to more excitement in my own learning, having experienced the power of a student-centred approach.

Kim's pedagogical belief and the focus on examination achievements were certainly rooted in many years of successful schooling, and reinforced in the initial Teaching Practicum in a school where students shared similar values about examination scores. When challenged by students' disengagement, Kim was forced to choose between giving up and finding new pathways. The first part of the account echoed the metaphors of the caged bird and the struggling soldier. Kim's desire for the students' future success was seen to be antagonized by the failure with a teachercentred approach. For those who persevere to seek the way forward, new learning often begins with a sense of getting stuck in confusion. The turning point, as gradually illuminated in our collaborative analysis, came again with timely support from the practicum supervisor who recognized Kim's frustrations.

Paradoxically, in desperation, Kim was liberated to look for new alternatives, and it was with such liberation that s/he began to see the real learning needs of students. It was no small discovery for Kim to claim that s/he was the one who should learn from students about learning attitude. Confronting the blocking obstacles, support was not about bringing the struggler to the comfort zone, but about perseverance for a breakthrough. The case concluded with a powerful food metaphor to explain the transformed understanding.

\section{Transformation of Relationships}

This study has been grounded in our shared concerns about the challenges for teacher educators. Our knowledge can be constructed metaphorically with an iceberg image (Figure 1), showing a relationship between the visible part of the documented curriculum, which is intentional and rational, and the submerged invisible lived curriculum, which is unplanned and contextual. Over many rounds of dialogue on the data, we discovered that liberation to learn always comes with transformation of relationships, conceptually as well as interpersonally.

Within the visible part, we had to build a relationship between the school curriculum and the curriculum of the pedagogy course. The three episodes illustrated the flow of our own learning as teacher educators, when dialogues put us in touch with the relationship between different stages 
of student teachers' learning journeys for knowledge-construction, before, during and after the Teaching Practicum. However, the dynamics in transformation of relationships could not be fully depicted in the iceberg metaphor, calling for new metaphors.

$<$ insert Figure 1 $>$

\section{Conflicts as Ignition of Inquiry}

Our own collaborative learning began with our encounter of conflicts. Even with our best consideration to present a curriculum with a self-justified design, we learned about its effect only by attending to students' voices. Learning did not take place in a classroom setting where expository talk about why and how the assessment tasks were to be fulfilled. In all episodes, when difficulties were encountered there was a common urge to avoid them. Sometimes students felt trapped in frustrations or even blames (from within or from external pressures). Cream just wanted to finish the assessment task without delay from more group discussion. Astor collapsed with a loss of confidence. Kim was inclined to join others to blame the students.

So much of the well-intended assertion about assessment for learning was not sufficient to change the mindset that assessment tasks were to be administered as requirements to be fulfilled. The unexpected circumstances challenged their responses. This move from an administrative stance to a learning stance required significant mentorship and timely support.

The outbreak of each conflict inevitably led to repercussions of further conflicts. The pedagogy of critical discourse found a place only with the succinct honest expression of Cream. Likewise, the nature of conflicts was unknown to either Astor or the teacher educator, when the scenario was a shock to both in different ways. As Kim's fantasy for successful teaching with teacher-centered approach evaporated, more conflicts arose.

Knowledge-construction is the central task for each respondent to an outbreak of conflict, beginning with the internal discourse with oneself. In essence, conflicts challenge assumptions of the teacher educators, and also urge student teachers to confront old beliefs in order to validate their personal practical knowledge. Transformation takes place in relationship-building between new experience and evolving knowledge. From addressing conflicts comes joint ownership of new discoveries.

\section{A Pedagogical Shift}

The intended transformation expected of the Liberal Studies curriculum requires an epistemological paradigm shift from transmission of knowledge to constructivist orientation to knowledge-making. With critical dialogue as the engine to address conflict outbreaks, onward journeying comes with the fuel of rapport-building, while knowledge is re-constructed in a learning space of a developing community. This paradigm shift has been captured by Mayo (2013, p. 11):

The roles of educator and learner are almost interchangeable, as all learn from each other, but this is not to say that the learner and educator are on an equal footing. The latter must have a certain amount of authority (bestowed on the educator by the learner because of the former's competence in the field of learning and as a pedagogue) which should not be allowed to degenerate into authoritarianism lest the spirit of genuine dialogue would be destroyed. Only through dialogue does the group learn collectively to meet the contradictions that underlie the reality being focused upon. 
Mayo's elucidation of the significance of dialogue clearly differentiates between authority and authoritarianism, without eroding the mentoring and supportive role of the teacher educator. A constructivist approach to teaching and learning fundamentally expects transformation of human relationship.

As the course instructor, I often wondered whether my expectation of critical discourse was more of an imposition than respect of my students' state of being. Perhaps my 'rich' experiences from the past gave me challengeable assumptions for validation. To me, transformation involves disconnection, followed by re-connection in relationship-building over my internal dialogue. Recognition of our own vulnerability was precisely what could equip us to understand our students' puzzles. We can then re-establish what Palmer (1998) described as a teacher's integrity that can revitalize the courage to teach. Liberated from a negative feeling towards vulnerability, we can empower students to begin their quest anew.

\section{Towards a Growth Model for Liberation of Learning}

As teacher educators, we care about our performance in the accountability system, just as our student teachers care about how they are assessed. Paradoxically, performance indicators tend to invite denial of complexity of teaching and learning. Successful teacher performance is expected to be operationalized in rational planning and efficient implementation with expectation of effective learning outcomes. Any unexpected circumstances not aligned with the intended flow can easily be registered in the system as signs of weakness or even failure. Likewise, conflicts, puzzles, gaps and dissonance are often associated with negative sentiments. To satisfy the requirement for expected performance, labor-intensive habits of reflection and reflexivity would be considered redundant.

The polemic view of success and failure does not tolerate much space between problem and resolution. The tendency to be success-oriented may ironically inhibit the kind of learning which calls for deeper understanding of the nature of the issues. For instance, Cream's resistance against collaboration actually opened up a neglected dialogue, whereas Astor was not failing in any absolute sense when students were disconnected from the teacher talk. Likewise, Kim's disappointment with what s/he saw as beasts in the jungle became a propelling force to challenge the long-standing belief, followed by transformation of pedagogical practice and renewed relationship with students. Each crisis became an opening for a serious search into the nature of the issue. By claiming the responsibility of learning, the teacher's sense of failure to drag students to where they do not want to go can become precisely a pivotal point for change. Often, the desire to be rewarded with a sense of achievement can reduce the space for learning, whereas a community can provide a space for collective quest of deeper meanings of nuances of 'failure'. A growth model recognizes the time and space needed by each student teacher for blossoming.

\section{Conclusion}

This paper focuses on the quest for pivotal points for change - how teacher educators and student teachers can be liberated to learn. As teacher educators, we feel the weight of responsibilities to nurture a younger generation of teachers. With an iceberg view of our inquiry outcomes, we are ready to take on a growth model as a fuller representation of the relationship between liberation and transformation. To conclude, we echo comments from Freire (Shor \& Freire, 1987, p.13):

...the dominant ideology 'lives' inside us and also controls society outside. If this domination inside and outside was complete, definitive, we could never think of social transformation... We can struggle to become free precisely because we can know we are not free! 
This study depicts the consciousness that makes liberation possible. By claiming our responsibilities to understand student teachers and struggle with them, we can reach the sight of experiences from their perspectives, and come to see the dialogic relationship between struggle, transformation and liberation.

\section{Acknowledgement}

We thank Sisi Wang for research assistance.

\section{References}

Almonte-Acosta, S. A. (2011). Pedagogical approaches to citizenship education in the varied contexts of secondary schools in the Philippines. In K. Kennedy, W.O. Lee \& D. Grossman (Eds.), Citizenship Pedagogies in Asia and the Pacific (pp. 175-201). Hong Kong: Comparative Education Research Centre, The University of Hong Kong, and Dordrecht: Springer.

Bray, M., \& Koo, R. (Eds.) (2004): Education and society in Hong Kong and Macao: Comparative Perspectives on Continuity and Change. Hong Kong: Comparative Education Research Centre, The University of Hong Kong, and Dordrecht: Kluwer.

Chan, Y. Y., \& Watkins, D. (1994). Classroom environment and approaches to learning: An investigation of the actual and preferred perceptions of Hong Kong secondary school students. Instructional Science, 22(3), 233-246.

Curriculum Development Council (2001). Learning to learn: Life-long learning and wholeperson development. Hong Kong: Government of the Hong Kong Special Administrative Region of the People's Republic of China.

Curriculum Development Council (2002). Basic education curriculum guide: Building on strengths (Primary 1 - Secondary 3). Hong Kong: Government of the Hong Kong Special Administrative Region of the People's Republic of China.

Curriculum Development Council \& Hong Kong Examinations and Assessment Authority (2007). Liberal Studies Curriculum and Assessment Guide (Secondary 4 - 6). Hong Kong: Curriculum Development Council \& Hong Kong Examinations and Assessment Authority.

Delors, J. (Chairperson) (1996). Learning: the treasure within. Paris: UNESCO.

Deng, Z. (2009). The formation of a school subject and the nature of curriculum content: An analysis of liberal studies in Hong Kong. Journal of Curriculum Studies, 41(5), 585-604.

Education Commission (1999). Learning for life (Review of Education System: Framework for Education Reform). Hong Kong: Printing Department of Hong Kong Special Administrative Region Government.

Education and Manpower Bureau (EMB) (2004). Reforming the academic structure for secondary education and higher education - actions for investing in the future. http://www.emb.gov.hk/FileManager/EN/content_4034/main.pdf/

Education and Manpower Bureau (2005). The new academic structure for senior secondary education and higher education-Action plan for investing in the future of Hong Kong. Hong Kong: Education and Manpower Bureau. 
Fung, D., \& Howe, C. (2012). Liberal Studies in Hong Kong: A new perspective on critical thinking through group work. Thinking Skills and Creativity, 7(2), 101-111.

Fung, C.L, \& Yip, W.Y (2010). The policies of reintroducing Liberal Studies into Hong Kong secondary schools. Educational Research for Policy and Practice, 9(1), 17-40.

Ho, I. T., Salili, F., Biggs, J. B., \& Hau, K. T. (1999). The relationship among causal attributions, learning strategies, and level of achievement: A Hong Kong Chinese study. Asia Pacific Journal of Education, 19, 44-58.

Kathard, H. (2009). Personal truth making: A cautious celebration. In R. Dhunpath, \& M. Samuel, (Eds.), Life history research: epistemology, methodology and representation. Rotterdam: Sense Publishers.

Kennedy, P. (2002). Learning cultures and learning styles: myth-understandings about adult (Hong Kong) Chinese learners. International Journal of Lifelong Education, 21(5), 430445.

Kwo, O. (2010). From SET to STELT: seeking the meaning of learning as a community for curriculum development, in Kwo. O. (Ed.), Teachers as Learners: critical discourse on challenges and opportunities. Hong Kong: Comparative Education Research Centre, The University of Hong Kong, and Dordrecht: Springer, 153-176.

Lee, K. (2007). Online collaborative case study learning. Journal of College Reading and Learning, 37(2), 82-100.

Macfarlane, B. (2012). Intellectual leadership in higher education: renewing the role of the university professor. New York: Routledge

Mayo, P. (2013). Echoes from Freire for a critically engaged pedagogy. London: Bloomsbury.

Morris, P. (1985). Teachers' perceptions of the barriers to the implementation of a pedagogic innovation: A South East Asian case study. International Review of Education, 31(1), 318.

Morris, P. \& Scott, L. (2005). Education reform and policy implementation in Hong Kong, in Ho, L.S., Morris, P. \& Chung, Y.P. (eds.), Education reform and the quest for excellence: the Hong Kong Story. Hong Kong: Hong Kong University Press, pp.83-98.

Palmer, P.J. (1998). The Courage to Teach: Exploring the Inner Landscape of a Teacher's Life. San Francisco: Jossey-Bass.

Ng, P. T. (2008). Educational reform in Singapore: From quantity to quality. Educational Research for Policy and Practice, 7(1), 5-15.

Shor, W. \& Freire, P. (1987). A pedagogy for liberation: dialogues on transforming education. Westport, Connecticut: Bergin \& Garvey.

Vygotsky, L.S. (1978). Mind in Society: The Development of Higher Psychological Processes. Cambridge: Harvard University Press.

Yackel, E., \& Cobb, P. (1996). Sociomathematical norms, argumentation, and autonomy in mathematics. Journal for research in mathematics education, 27(4), 458-477. 


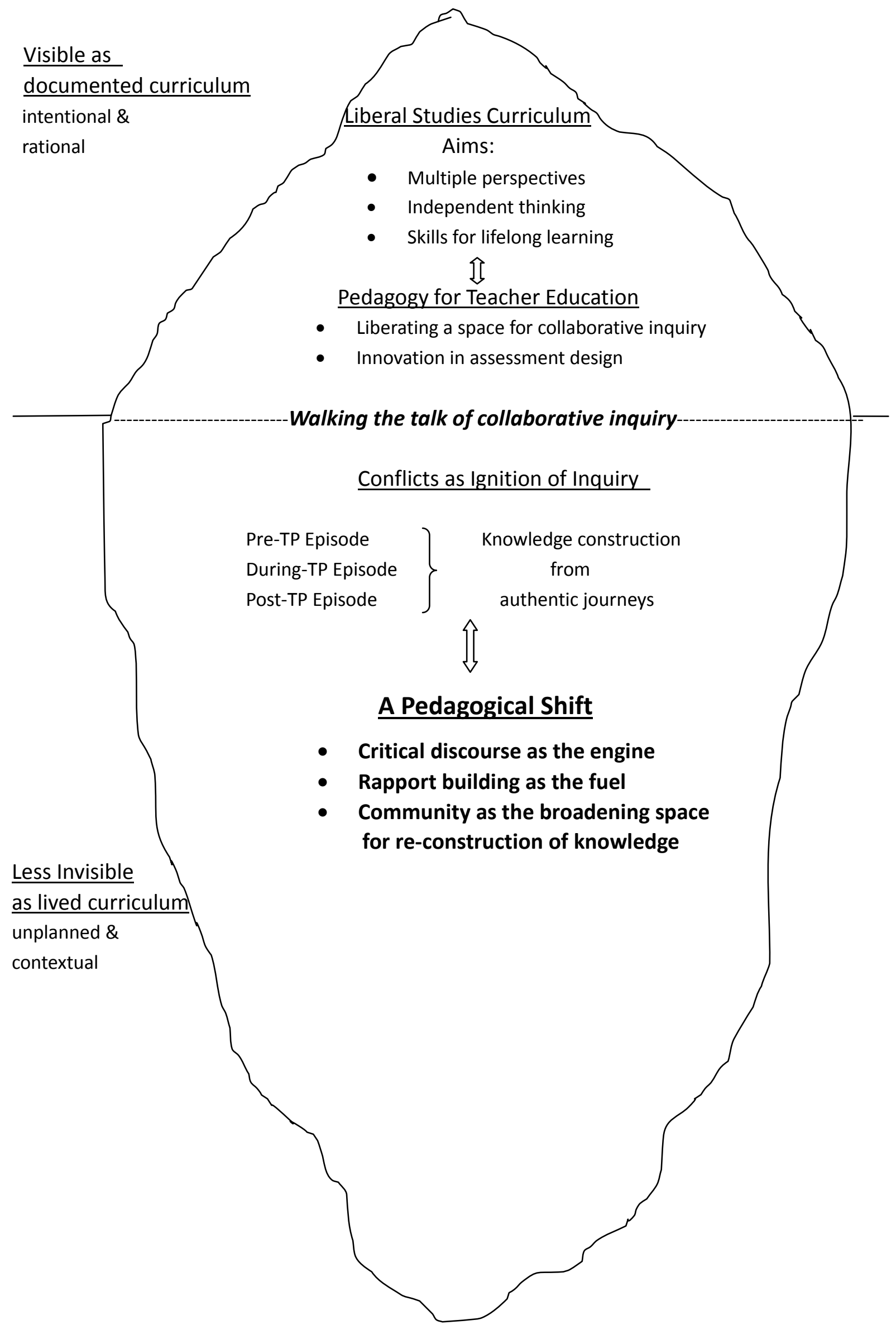

Figure 1: An Iceberg View of the Dynamics of Relationships 